\title{
MODERN APPROACHES TO THE ISSUE OF MENTORING
}

\author{
Auzhanova G. G., Teacher-moderator, Nazarbayev Intellectual school of the chemical and biological \\ direction of the city of Pavlodar, Republic of Kazakhstan \\ Dauletkulova D. O., Teacher-moderator, Nazarbayev Intellectual school of the chemical and \\ biological direction of the city of Pavlodar, Republic of Kazakhstan
}

\section{DOI: https://doi.org/10.31435/rsglobal_conf/25032021/7463}

Abstract. The 21st century school should have competitive specialists who can provide students with quality education. How can this be achieved? It is necessary to create such an active environment so that teachers feel motivated to develop and improve professionally; this contributes to the cooperation of the mentor and the mentee.

This article raises the issue of mentoring, which has recently begun to be actively implemented in the education system of the Republic of Kazakhstan. The authors consider the differences between mentoring and coaching, describe in detail the stages of the collaboration, their goals and set tasks. The article is based on the practical experience of the authors gained in the process of working with mentees in the school.

Keywords: mentoring, mentor, mentee, cooperation, mentoring, professional adaptation.

"Общество, способное использовать идеи, появляющиеся в сознании отдельного индивидуума, для роста возможностей общества как целого, и использующее рост возможностей общества, как целого, для формирования индивидуума, способного генерировать новые идеи, - будет обладать наиболее быстрым темпом роста возможностей" [1, с. 178].

Согласитесь, таких "индивидуумов" чаще всего "находят", раскрывают, "выращивают" именно в школе; и в этих условиях роль учителя как никогда огромна и значима. Поэтому мы соглашаемся с мнением, что "... школе нужен профессионально компетентный, самостоятельно мыслящий педагог, психически и технологически способный к реализации гуманистических ценностей на практике, к осмысленному включению в инновационные процессы..." [3].

Думаем, каждому руководителю школы хотелось бы, чтобы именно в его коллективе были конкурентоспособные специалисты. А как добиться этого? Хороший руководитель, естественно, создаст такую деятельную среду, когда у подопечных возникнет желание развиваться, совершенствоваться. Вот тогда-то приходит на помощь менторство. Что такое менторство? Чем оно полезно в современной школе? В литературе по данной теме находим следующее: "На Западе сегодня чрезвычайно популярна практика менторства - ее считают крайне полезной для развития карьеры". [4] В онлайн-словаре написано, что "менторство - это наставничество". [5] Так ли это? По нашему мнению, между менторством и наставничеством все-таки есть различия.

Наставничество, на наш взгляд, предполагает работу именно со стажером, для которого важна профессиональная адаптация. "Для молодого специалиста вхождение в новую деятельность сопровождается высоким эмоциональным напряжением, требующим мобилизации всех внутренних ресурсов. Решить эту стратегическую задачу поможет создание гибкой и мобильной системы наставничества, способной оптимизировать процесс профессионального становления молодого учителя, сформировать у него мотивации к самосовершенствованию, саморазвитию, самореализации. В этой системе отражена жизненная необходимость молодого специалиста получить поддержку опытного педагога наставника, который готов оказать ему практическую и теоретическую помощь на рабочем месте и повысить его профессиональную компетентность". [3] А о менторинге мы находим такое определение: "Менторинг - длительный процесс создания доверительных, личностно заинтересованных взаимоотношений между ментором и подопечным, направленный на достижения у последнего существенной динамики в совершенствовании знаний, мышления, эффективности практических действий с целью его профессионального становления, как целостной личности педагога" [2, с. 230].

"Зачем нужно менторство?... Чтобы расти в нужном направлении. Почему нельзя просто книжку почитать? Книжка - это хорошо, но она не даст обратной связи, не подскажет - не сбился ли с пути. К тому же, некоторые знания автор просто мог не суметь сформулировать. Если ему задать конкретный вопрос - какие могут быть проблемы в таком-то 
конкретном случае и как их избежать - он ответит, даже если про такой случай никогда и не думал. С другой стороны, если автор про него не думал, то и в книжке не опишет" [6].

Итак, менторинг - процесс очень важный и эффективный. Он способствует достижению существенных результатов при приобретении новых знаний, нового опыта; развитию профессионального роста, уверенности в себе и, наконец, позволит "учителю достичь успешности в своей работе" [2, с. 230]. При этом ментор и менти ставят перед собой определенные задачи. Они могут совпадать, но между задачами ментора и менти есть различия.

Наш опыт работы в качестве ментора позволил выделить следующие задачи ментора:

- научить своего подопечного эффективно использовать его (менти) имеющийся творческий и интеллектуальный потенциал;

- поделиться своими знаниями и опытом с менти;

- в ходе совместной творческой деятельности давать необходимые рекомендации, а если в этом есть необходимость, то и поддержать, поощрить.

При этом менти ставит перед собой следующие задачи: уровень;

- развивать свои профессиональные навыки с целью перехода на новый, более высокий

- совершенствовать предметные и профессиональные знания и умения.

Менторинг будет продуктивным, если будут соблюдены некоторые условия: ментор проявит желание помочь менти, используя свой опыт и знания; подопечный - желание улучшить свои профессиональные качества. Надо подчеркнуть, что совместная деятельность принесет действительный успех еще и тогда, когда между ними будет соблюдаться закон общения: взаимное доверие, уважение, искренность, честность...

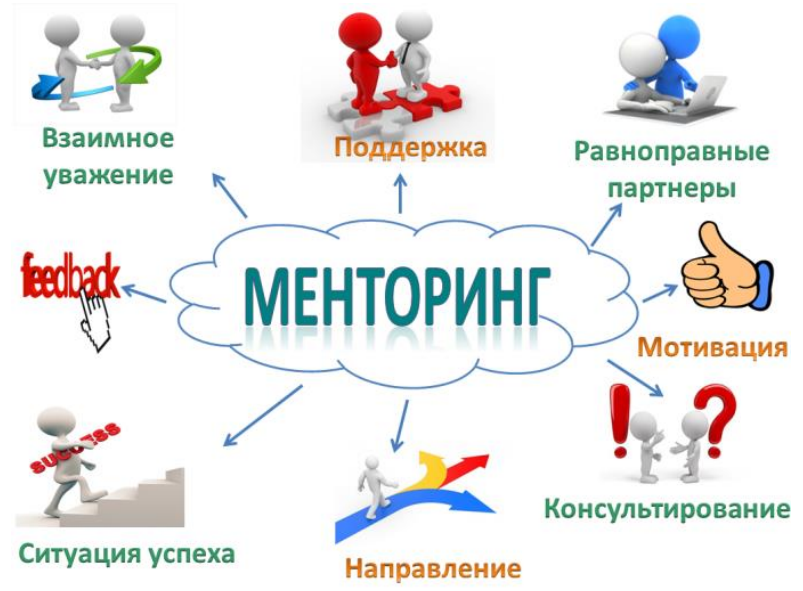

Рис. 1 Способы поддержки менти.

Какие способы поддержки молодого учителя можно использовать, чтобы менторинг был эффективным?

Во-первых, нужно выстраивать свои отношения на взаимном уважении и доверии, пребывать в состоянии постоянного диалога, взаимодействовать.

Во-вторых, безоценочное восприятие. Это очень важно, так как способствует тому, что менти открыто выражает свои мысли, не боится быть отвергнутым или не понятым.

B-третьих, равноправные партнеры, готовые учиться друг у друга. Между ментором и менти не должно быть отношений в формате "начальник - подчиненный".

Кроме того, ментор должен быть немного психологом. Он должен уметь видеть, нуждается ли в поддержке молодой специалист, и поддержать его в нужный момент. "Все мы люди и иногда слова "у тебя все получится" могут сыграть огромную роль в процессе, нежели все другие методы», - пишет О. Дятел [7, с. 20].

Также мы советуем, направляем, но не даем готовых решений. Самое главное, никогда не навязываем своего мнения. Менти должен осознать, что все решения принимает он сам и их последствия лежат на нем.

Обратная связь позволяет поддерживать сотрудничество между ментором и менти, при этом она может быть как в устной, так и в письменной форме. Хороший фидбэк мотивирует и 
вдохновляет человека, у него появляется желание что-то улучшить. Он должен быть глубоким, не оценивать только как хорошо/плохо, а основываться на конкретных примерах и фактах. И самое главное, в обратной связи не должно быть осуждения.

При работе с менти мы используем коучинговый подход, в первую очередь, открытые вопросы и консультирование:

$>$ Что могло привести к этой ситуации?

$>$ Какие шаги вы можете предпринять?

$>$ Что вы готовы с этим сделать?

$>$ Как вы поймете, что сделали это правильно?

$>$ Как бы вы иначе подошли к решению данной проблемы?

Такой мониторинг позволяет понять прогресс молодого учителя и зоны его развития и вовремя скорректировать его маршрут.

Важную роль, на наш взгляд, в менторинге играет и рефлексивный дневник, которую ведут (не обязательно, но желательно) и менти, и ментор. Рефлексивный дневник позволит учителям анализировать учебный процесс, процесс сотрудничества и деятельности. При этом дневник поможет в дальнейшем обнаружить какие-либо проблемы, которые не сразу можно увидеть.

По нашему мнению, менторинг можно разделить на неопределенное количество циклов. Все зависит от проблем, которые предстоит решить менти с помощью ментора, более опытного коллеги. Так, одна проблема - один цикл, который не ограничен временем. Все зависит от самой проблемы, объективных и субъективных условий, которые окружают наших преподавателей. Каждый цикл состоит из нескольких этапов (стадии, фаз):

1-й этап - этап определения (выявления) проблемы. На этом этапе конкретизируется цель в зависимости от содержания проблемы, ставятся задачи.

2-й этап - этап обучения (консультации): поиск путей решения проблемы (определение стратегий, методов, приемов); демонстрация ментором своего опыта в качестве примера.

3-й этап - этап действия (демонстрации) менти. Этот этап можно назвать отчетным: менти демонстрирует свои достижения...

4-й этап - этап рефлексии, когда происходит анализ собственных мыслей, действий; самоотчет; самопознание; самооценка. Именно этот этап станет, как нам кажется, источником новых идей, новых проблем.

Надо сказать, что менторинг благотворно влияет не только на менти, но и на ментора. Менторинг является инструментом для личностного и профессионального роста не только менти, но и ментора, так как стимулирует собственное развитие и является источником обретения новых навыков. Как-то нам попалось высказывание из Талмуда: "Многому я научился у своих наставников, еще большему - у своих товарищей, но больше всего - у своих учеников". Думаем, эти слова относятся и к рассматриваемому вопросу. Так, в процессе сотрудничества ментор не только обучает своего коллегу, но и сам получает некоторый опыт. Ментор в ходе сотрудничества будет "...впитывать свежие идеи (и знания) от молодых и амбициозных сотрудников, тех, кто сам движется вперед; следить за современными достижениями, чтобы быть на высоте; пересматривать собственные профессиональные интересы, находить новые неожиданные направления; устанавливать контакты с другими менторами для обмена опытом..."; а также "почувствует на себе, с какими проблемами сталкиваются молодые сотрудники; получит хорошие навыки наставничества, необходимые в работе со своими подчиненными; удовлетворит собственные амбиции, потребность делиться своими знаниями и опытом; ощутит свою нужность" [8].

Да, процесс менторской работы "пошел" в школы. Он внедряется слушателями уровневых курсов. И как важно, чтобы эта работа не погасла, не остановилась, не фигурировала лишь на бумаге (как это зачастую бывает) в виде отчетов. Практика показала (хотя бы и та, которую проводили слушатели уровневых курсов), что такое сотрудничество действенно, эффективно. Надо помнить, что менторинг "...позволяет субъекту следовать по пути старших и мудрых коллег, которые могут передать знания, опыт и "открыть двери" к высшим возможностям" [2, с. 230].

"Огонь разжигается огнём, а личность формируется личностью. Стань ярким примером и бесспорным авторитетом для своих подопечных! Будь незаурядным, интересным человеком и все получится!" (С. Б. Елканов) Как актуальны эти строки в наше время! 


\section{ЛИТЕРАТУРА}

1. А.А. Жайтапова, Г.А. Рудик, Е.В. Белошниченко, А.С. Сатывалдиева. Педагогика 21-го века на пороге школы. Информационно - методический дайджет - Алматы, 2009. 302 с.

2. Руководство для учителя. Второй (основной) уровень. Издание третье. -Астана, 2015г. 294 с.

3. Организация наставничества в школе. [Электронный pecypc] URL: http://www.resobr.ru/materials/370/5174/ (дата обращения 04. 07. 15)

4. Римма Авшалумова. Менторинг в развитии карьеры. [Электронный ресурс] URL:http://hrm.ru/mentoring-v-razvitii-karery (дата обращения 29. 06. 15)

5. Исторический словарь галлицизмов русского языка. Менторство. [Электронный ресурс] URL:http://gallicismes.academic.ru/24295/ (дата обращения 03. 07. 15)

6. Менторинг. Начни - сайт об ответственном отношении к настоящему и будущему. Начни с себя. [Электронный pecypc] URL:http://www.nachni.com/tiki-read_article.php?articleId=41 (дата обращения 29. 06. 15)

7. Пособие для менторов. Равный равному. Киев, 2015 [Электронный pecypc] URL:http://inshaosvita.org/wp-content/uploads/2015/10/Handbook-PeerToPeer_RU.pdf (Дата обращения 10.12.2019).

8. Каково быть другом Одиссея, или Что такое менторинг? [Электронный pecypc] URL: http://www.pro-personal.ru/journal/696/303335/ (дата обращения 04. 07. 15)

9. Что такое формативное оценивание и каким образом оно улучшает преподавание и обучение? [Электронный pecypc] URL: https://internationalconference.ru/images/PDF/2016/19/chto-takoeformativnoe-otsenivanie.pdf 